\title{
Water treatment technology performance for chemical enhanced oil recovery: modeling, simulation and optimization
}

\author{
Mahdi Chemil $^{1} \cdot$ Zahia Zizi $^{1}$ [D $\cdot$ Nadjib Drouiche $^{2} \cdot$ Mohamed Khodja $^{3} \cdot$ Moundher Hadji $^{3}$
}

Received: 1 June 2021 / Accepted: 29 July 2021 / Published online: 6 August 2021

(C) The Author(s) 2021

\begin{abstract}
The use of ASP (alkali-surfactant-polymer) slug could be affected by the use of high hardness water, especially when injecting an alkaline agent $\left(\mathrm{Na}_{2} \mathrm{CO}_{3}\right)$. The injection water quality of the TFT field is not adequate for cEOR (chemical enhanced oil recovery), because it contains a high hardness rate up to $160^{\circ} \mathrm{f}$ (report DC R\&D 2019). With a TDS rate varying between 4 and $6 \mathrm{~g} / \mathrm{l}$, it could cause a formation of insoluble complexes with alkaline agents, and on the other hand, the decrease in the performances of the injected surfactants and polymers. In this work, a simulation study was carried out in order to identify the most adequate treatment process between NF (nanofiltration) and RO (reverse osmoses). The performance of the 4040 type membrane modules has been tested under different operating conditions of temperature and feed pressure $\left(25^{\circ}-45^{\circ}\right)$ and (3.1-22 bar), respectively. Several membrane configurations $(6: 0,4: 2)$ have been tested to determine their effect on the process' performance. The results showed that the NF90 4040 presents the best performances toward the requirements of the cEOR. Furthermore, the membrane configuration effects the quality of permeate and recovery rate. The results showed a rejection rate of $90 \%$ and $95 \%$, respectively, for the total hardness $\left(\mathrm{Ca}^{2+} \mathrm{and}_{\mathrm{Mg}}{ }^{2+}\right)$ and the sulfate.
\end{abstract}

Keywords Chemical enhanced oil recovery $\cdot$ ASP sludge $\cdot$ Modeling $\cdot$ Water treatment $\cdot$ Reverse osmosis $\cdot$ Nanofiltration

\section{Introduction}

During oilfield exploitation, several constraints appear, making oil recovery less efficient. According to oil experts, more than $60 \%$ of crude oil still trapped into the reservoir rocks after the secondary recovery (water injection for sweep and maintaining pressure) (Zaid et al. 2014). Lately, several oil \& gas companies expressed interest in water treatment technologies to develop EOR projects. Henthorne (2013) reported that water-based EOR potential was estimated at 750 billion barrels. Morrow and Buckley (2011) explained the growth of interest on water technologies by the number of publications on low salinity water flooding (LSW) techniques. Nowadays in many oilfields, several companies

Zahia Zizi

zahia.zizi@univ-sba.dz

1 Laboratory of Advanced Materials and Physico-Chemistry for Environment and Health (MAPES), Djillali Liabès University of Sidi Bel Abbes, Sidi Bel Abbès, Algeria

2 National Center of Semi-Conductors Technologies and Energitic, El Harrach, Algiers, Algeria

3 Algerian Petroleum Institute, Boumerdes, Algeria expressed the need to proceed with enhanced oil recovery (EOR), in order to improve recovery rate and reduce the reservoir overflow problem that harms recovery efficiency. CEOR technology is categorized in two classes (Chang and Yamming 2013): polymer flooding and surfactant flooding. Various types are used, such as alkaline-surfactant-polymer (ASP) flooding, alkaline-cosolvant-polymer (ACP) flooding, and surfactant-polymer flooding (SP).

Reverse osmosis (RO) technology is used in the water purification process to separate dissolved solids and other large molecules from water. Typical applications of RO technology are seawater desalination, microelectronics production, laboratory testing, biotechnology, and other process that require highly purified water. In osmosis process, water with a lower concentration of solids naturally flows through a membrane to an area of higher concentration through naturally occurring osmotic pressure, equalizing the concentration of the solute on either side of the membrane. The RO technology applies pressure to a stream of water to overcome the natural osmotic pressure. The feed water is forced through a semi-permeable membrane, emerging as purified water and leaving behind a concentrated solution of dissolved solids. Therefore, RO system permeates have 
very low hardness and alkalinity, and therefore, it has quite high corrosion potential. The nanofiltrations (NF) are known by their higher water permeability than the RO membranes and significantly lower TDS rejection: from $95 \%$ down to non-significant. However, the NF membranes have sufficiently high rejection of selected constituents, such as hardness, metals and organic matters. Characterization RO NF reported that new insights can be reached regarding the best choice of membrane, based on the minimization of electrical conductivity and the ability to reject specific ions in different operating conditions.

Within the framework of EOR project initiated by SONATRACH, TFT oil field has been chosen during the screening phase for chemical EOR (cEOR) under certain criteria ( $\mathrm{T}^{\circ}$, TDS, permeability). Nevertheless, establishment of EOR project is very difficult, expensive and harmful. That is why, it is essential to conduct a feasibility study at pilot scale. cEOR performance depends on several parameters, such as the water quality, principally, when a chemical slug containing alkaline agent $\left(\mathrm{Na}_{2} \mathrm{CO}_{3}\right)$ is injected. However, the injected water at TFT field is not compatible with cEOR process. Due to high amount of hardness that could reach $160^{\circ} \mathrm{f}$ and TDS of 4-6 g/l (R\&D SONATRACH report 2017). To counter this problem, it is necessary to implement injected water treatment plant by several techniques. The aim of this work is overcome the incompatibility problem at TFT oil field between aquifer water named la LIAS groundwater and the slug ASP or SP (alkaline-surfactants-polymer or surfactant-polymer). The point is to compare between different water treatments techniques, namely: water softening by reverse osmosis and nanofiltration; in order to identify the most efficient technique toward cEOR.

\section{Modeling of RO process}

Due to availability of computational tools such as Aspen plus, Aspen Custom modeler, gRPROMS, Matlab, there has been growing implementation of model based activities in process design and operations over the past decades. Tanvir and Mujtaba (2017) recently presented one-dimensional model for RO process to evaluate the impact of operating conditions on the rejection of organic and nonorganic compounds. In this work, RO/NF-based process model will be used, Water Application Value Engine WAVE for design and optimization study. It is the industry's fully integrated modeling software program to integrate three of the leading technologies- ultrafiltration (UF), reverse osmosis (RO), nanofiltration (NF) and ion exchange (IX) into one comprehensive tool. Using a common interface, it simplifies the design process and ultimately helps reduce the time needed to manage water treatment system. The RO/NF process is modeled by a set of nonlinear algebraic equations (Dow, Water and Process Solutions, FILMTEC ${ }^{\text {TM }}$ Reverse Osmosis Membranes, Technical Manual 2021).

\section{Case study}

The design of the full-scale reverse osmosis/nanofiltration modules was performed using WAVE software from DOW Chemical. Different design patterns have been developed to reduce the TDS and hardness. One and two stage brackish RO modules and NF module are used to develop for the softened water treatment from above salinity of the water. RO brackish water membranes are a non-selective process that decreases the TDS, while the NF membranes are a selective process that decreases only bivalent ions. Both structures are same as shown in Fig. 1. And the characteristic parameters of the RO brackish module (BW30 4040, XLE 4040) and NF module (NF90 4040, NF270 4040) are presented in Table 1. For this work, both processes have 6 pressure vessels arranged in parallel for the stage 1 case. And $4 \mathrm{PV}$ arranged in parallel and $2 \mathrm{PV}$ in the stage 2 case. The flow requirements for the system were flow permeate output of $100 \mathrm{~m}^{3} /$ day. The design was constrained by limits on maximum permeate recovery factor of at most $75 \%$ as recommended by a membrane manufacturer to preserve a membrane lifetime. The salinity of input data is the same as the LIAS groundwater (3846 ppm of TDS and $340 \mathrm{ppm}$ of total hardness). Variation of temperature and feed pressure were carried out to fix the optimal operating.

\section{Water utilization}

Water treatment can be simple if good quality source water with low total suspended solids (TSS), low divalent ions, and no bacteria is available. In this case, only a simple filtration device is needed in the field. However, if the water quality does not meet the ASP slug specifications, then special equipment will be necessary to process the brine before usage (Morrow and Buckley 2011). In this case, brackish raw groundwater from LIAS aquifer is used for this simulation to mimic the real water injection at TFT field. An analysis of a water sample from the LIAS aquifer groundwater revealed a high amount of calcium, magnesium and sulfate, as detailed in Table 2. 
Fig. 1 Schematic design of $\mathrm{RO} / \mathrm{NF}$ configuration process. a Process with one stage. $\mathbf{b}$ Process with two stages

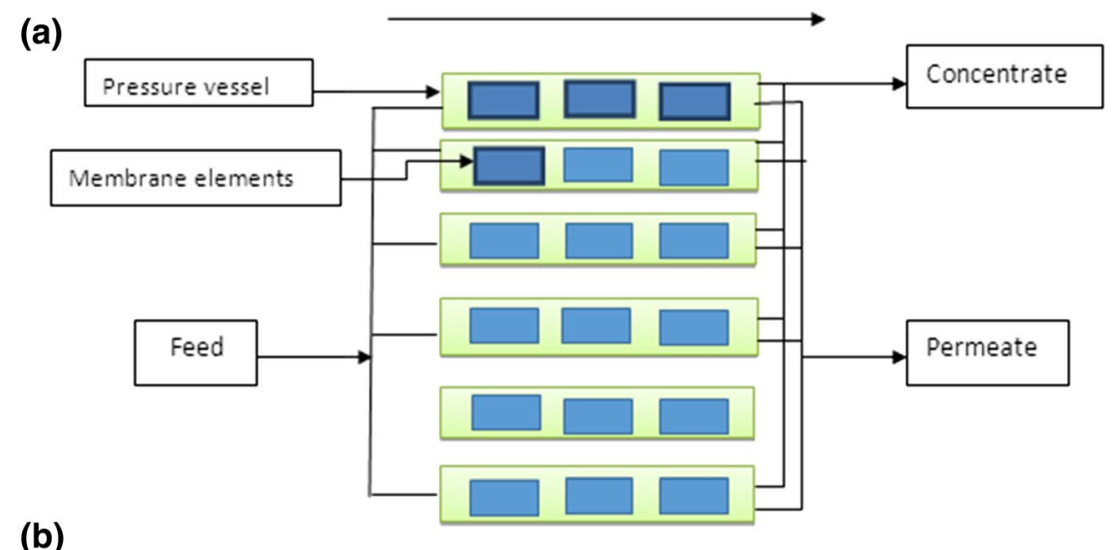

(b)

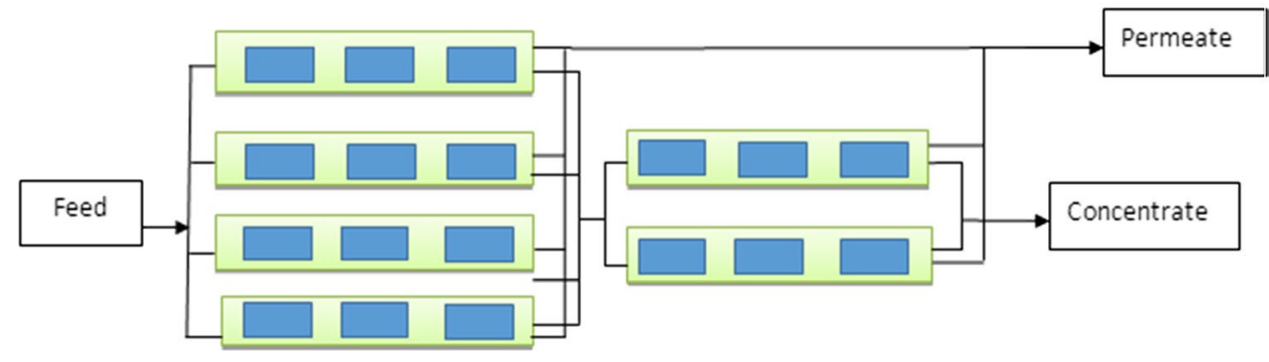

\begin{tabular}{|c|c|c|c|c|c|}
\hline \multirow[t]{2}{*}{ Elements } & \multicolumn{5}{|l|}{ Parameters } \\
\hline & $\begin{array}{l}\text { Active area } \\
\left(\mathrm{m}^{2}\right)\end{array}$ & $\begin{array}{l}\text { Max operating } \\
\text { pressure (bar) }\end{array}$ & $\begin{array}{l}\text { Max feed flow } \\
\text { rate }\left(\mathrm{m}^{3} / \text { hour }\right)\end{array}$ & $\begin{array}{l}\text { Permeate flow } \\
\text { rate }\left(\mathrm{m}^{3} / \mathrm{d}\right)\end{array}$ & Salt rejection $(\%)$ \\
\hline BW30 4040 & 7.2 & 41 & 3.6 & 9.1 & 99.5 \\
\hline XLE 4040 & 7.1 & 41 & 3.2 & 9.8 & 99.0 \\
\hline NE 2704040 & 7.6 & 41 & 3.6 & 9.5 & $>97.0$ \\
\hline NE 904040 & 7.6 & 41 & 3.6 & 7.6 & $>97.0$ \\
\hline
\end{tabular}

Table 1 Characteristics of membrane' elements membrane. XLE membrane required more feed pressure than NF90 membrane. The feed pressure required to achieve $75 \% \mathrm{RR}$ decreases with increasing temperature. This is due ions diffusion transport that increases with temperature causing the rising on water flux. Thus, increasing temperature causes flexibility of membrane chains and allowing more ions to migrate throw membrane pores (Al-Obaidi et al. 2018). Previous simulation results show that the optimum to feed pressure for each membrane BW30, XLE, NF90 and NF270 is 15 bar, 10 bar, 9 bar and 5 bar, respectively. Figures 4 and 5 exhibit the effect of temperature on recovery ratio at optimum feed pressure. As seen, the $\mathrm{NF} 270$ reached maximum RR at $40{ }^{\circ} \mathrm{C}$. It is noticed that all membranes reached around $75 \%$ of $\mathrm{RR}$ at $30{ }^{\circ} \mathrm{C}$.

Figures 6 and 7 show the effect of temperature on energy consumption at optimum feed pressure. The results demonstrate that BW30 membrane is the most energy consuming.

This is due to the highest required feed pressure. These results could serve as engineering tools to adjust operating to achieve $75 \%$ RR is obtained by BW 304040 membrane, while the lowest feed pressure is obtained by NF270 4040 
Table 2 Physico-chemical brackish LIAS groundwater quality

\begin{tabular}{lll}
\hline Constituent & Units & $\begin{array}{l}\text { Simulated } \\
\text { LIAS groud- } \\
\text { water }\end{array}$ \\
\hline Temperature & ${ }^{\circ} \mathrm{C}$ & $25-45$ \\
$\mathrm{Ph}$ & - & $7.5-8.1$ \\
Turbidity & $\mathrm{NTU}$ & $<1$ \\
Total hardness as $\mathrm{Ca}$ and $\mathrm{Mg}$ & $\mathrm{mg} / \mathrm{L} \mathrm{CaCO} 3$ & 993.85 \\
Chlorides & $\mathrm{mg} / \mathrm{L}$ & 1150 \\
Total dissolved solids & $\mathrm{mg} / \mathrm{L}$ & 3846.19 \\
Total suspended solids & $\mathrm{mg} / \mathrm{L}$ & $<1$ \\
Sulfate & $\mathrm{mg} / \mathrm{L}$ & 1200 \\
Calcium & $\mathrm{mg} / \mathrm{L}$ & 250 \\
Magnesium & $\mathrm{mg} / \mathrm{L}$ & 90 \\
Sodium & $\mathrm{mg} / \mathrm{L}$ & 900 \\
Potassium & $\mathrm{mg} / \mathrm{L}$ & 50 \\
Strontium & $\mathrm{mg} / \mathrm{L}$ & 5 \\
Nitrates & $\mathrm{mg} / \mathrm{L}$ & 20 \\
Bicarbonate & $\mathrm{mg} / \mathrm{L}$ & 160 \\
Carbonate & $\mathrm{mg} / \mathrm{L}$ & 0.19 \\
\hline
\end{tabular}

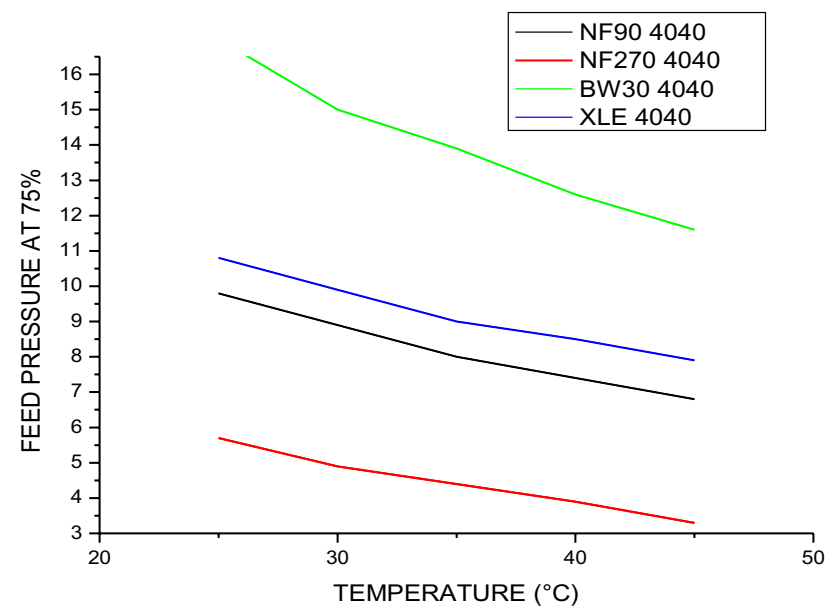

Fig.2 Effect of temperature on feed pressure to achieve $75 \%$ of RR for conf a

conditions in front of temperature changing at field during seasons to maintain the required recovery ratio and desired permeate composition (TDS, total hardness, sulfate concentration) without having recourse to heat exchanger in the aim to minimize energy consumption.

\section{TDS, total hardness and sulfate removal}

Total hardness and sulfate concentration are the most important parameter for water treatment regarding EOR process. Figures 8 and 9 show the effect of temperature on TDS, total

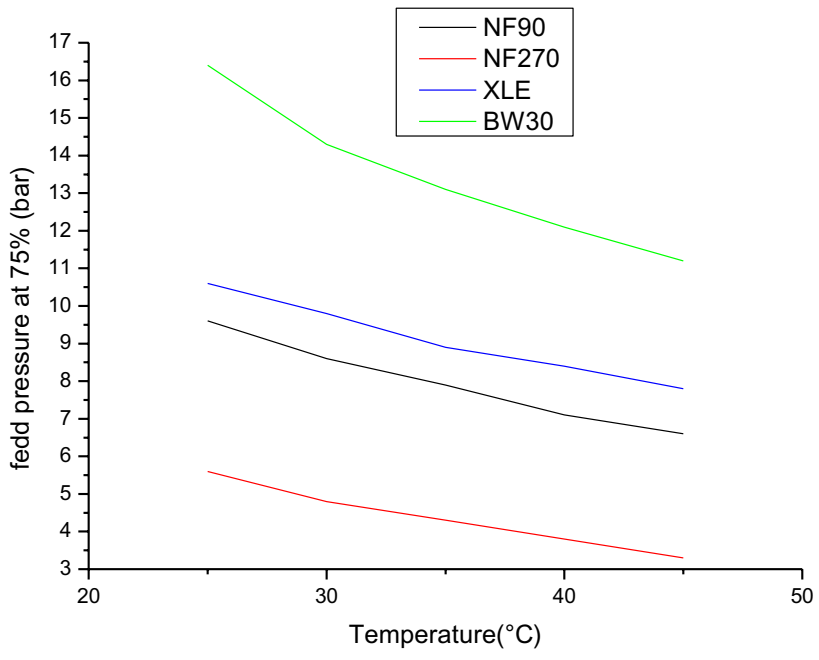

Fig. 3 Effect of temperature on feed pressure to achieve $75 \%$ of RR for conf $b$

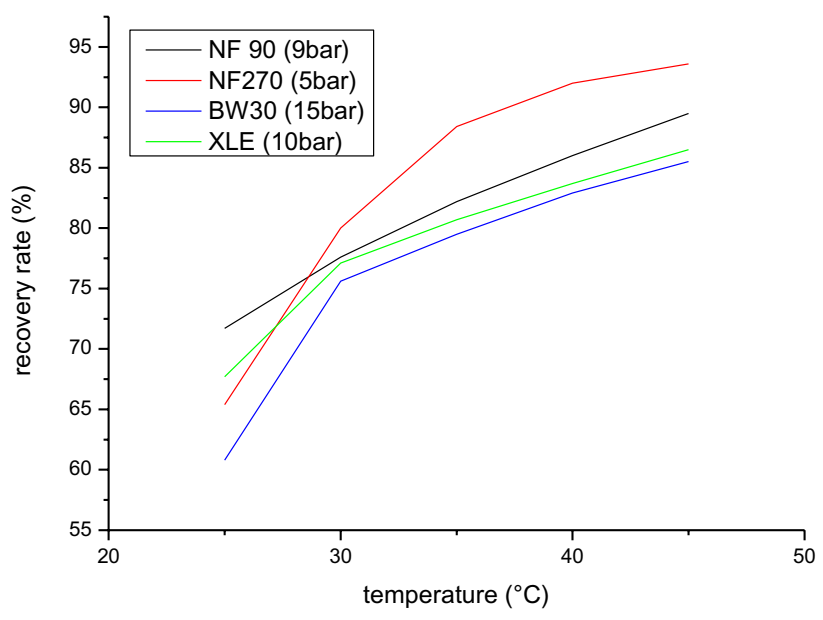

Fig.4 Effect of temperature on recovery ratio at optimum feed pressure for conf a

harness and sulfate removal, respectively, for stage 1 and stage 2 , respectively. The results demonstrate that increasing temperature causes decreasing in percentage removal of TDS, TH and sulfate. This is in agreement with increasing ions diffusion transport and the flexibility of membrane chains. RO membranes (BW30, XLE) show the highest TDS removal percentage, up to $99 \%$, while NF270 shows the lowest removal percentage, around 55\%. Results from Figs. 10 and 11 that exhibit TH removal percentage for stage 1 and stage 2, respectively, show that BW30 had the highest removal percentage, up to $99 \%$. However, NF 90 membrane shows slightly better removal percentage compared to RO membrane XLE. As expected, the highest removal \% is attributed to the tightest membranes. Insignificant difference 


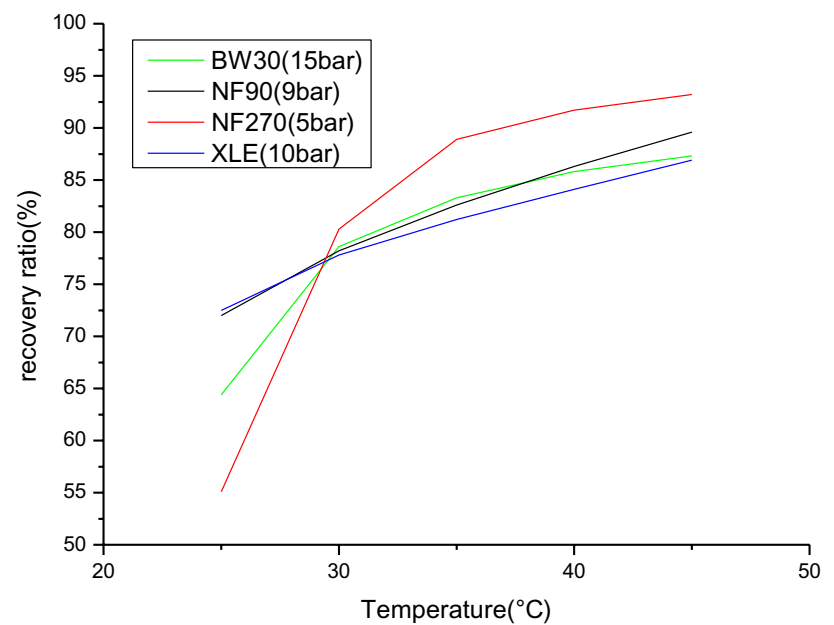

Fig.5 Effect of temperature on recovery ratio at optimum feed pressure for conf $b$

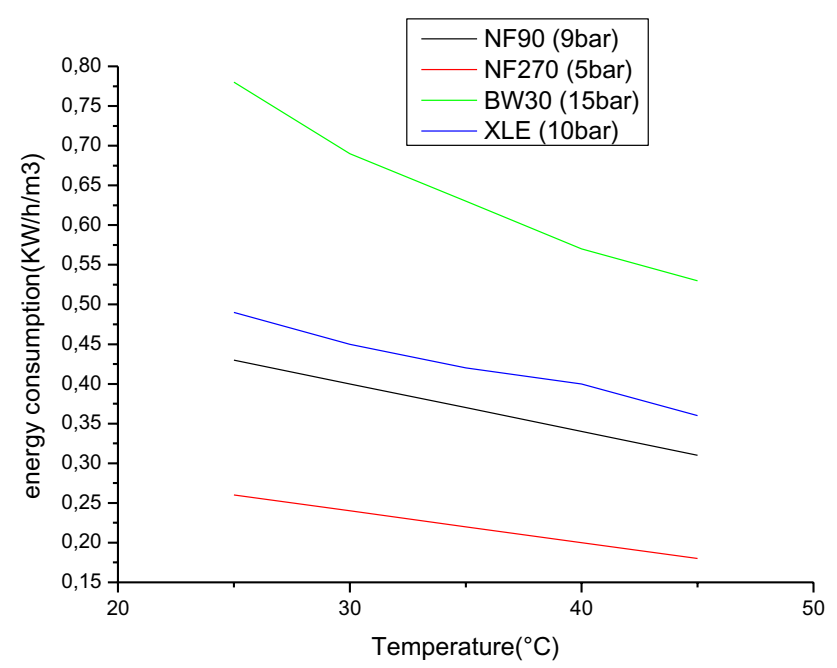

Fig.6 Effect of temperature on energy consumption at optimum feed pressure for conf a

was seen on sulfate removal percentage between RO and NF membranes; however, at $25^{\circ}$, NF270 shows slightly better removal \% regarding NF90 and XLE. But sulfate removal percentage decreased significantly at superior temperature as shown in Figs. 12 and 13. This is due to rapid increasing of water flux. (The RR increased from 55 to $80 \%$ for $25-30^{\circ} \mathrm{C}$, respectively.)

\section{Membrane choice}

We noticed from the previous results that RO process is more efficient than NF. The TDS, total hardness and sulfate removal percentage are quite higher with $\mathrm{RO}$ regarding NF. However, it is important to take into account the EOR

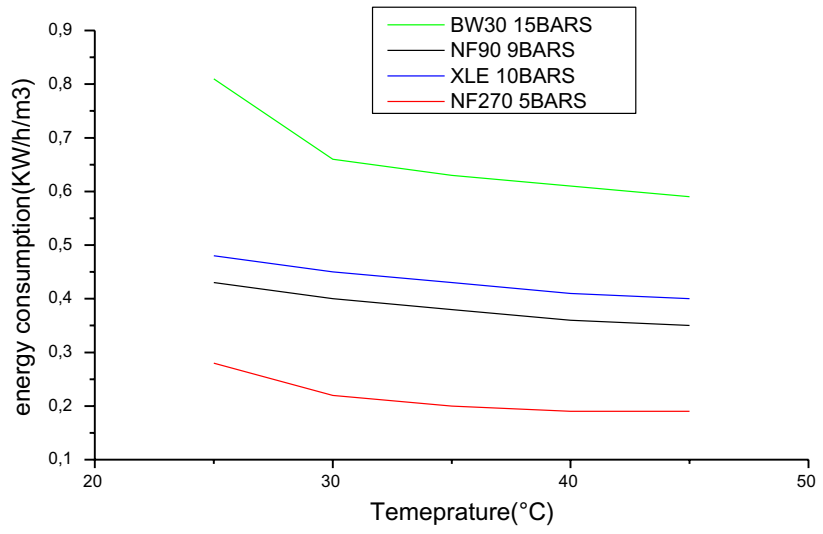

Fig. 7 Effect of temperature on energy consumption at optimum feed pressure for conf $b$

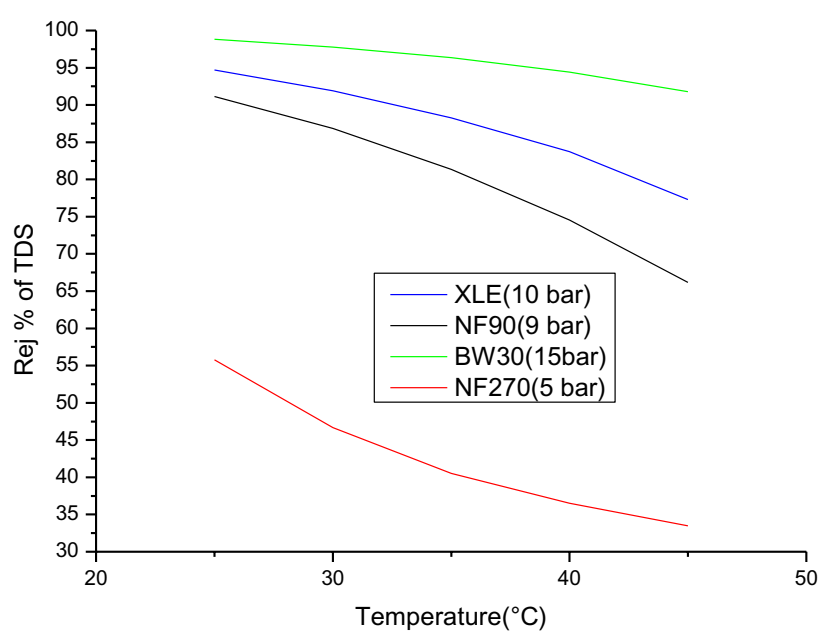

Fig. 8 Effect of temperature on TDS \% removal at optimum feed pressure for conf a

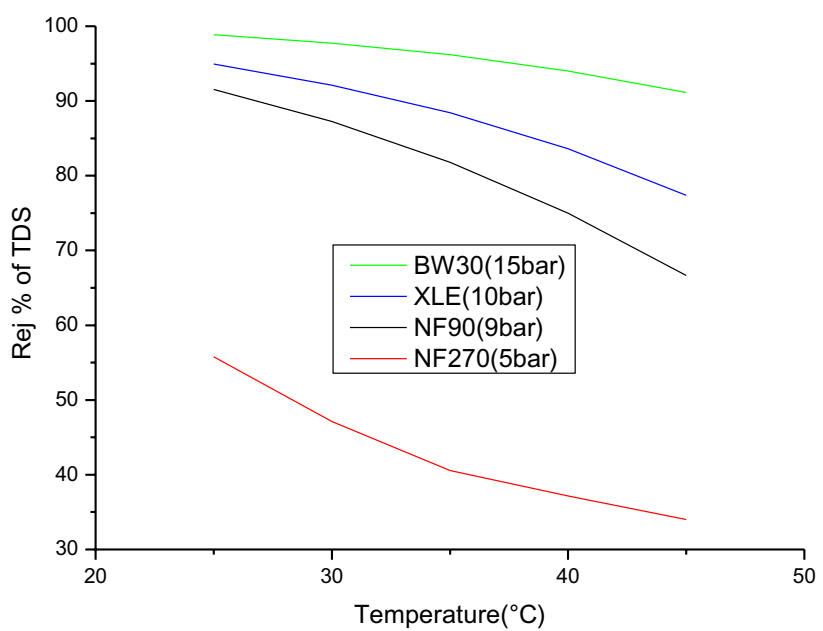

Fig. 9 Effect of temperature on TDS \% removal at optimum feed pressure for conf $b$ 


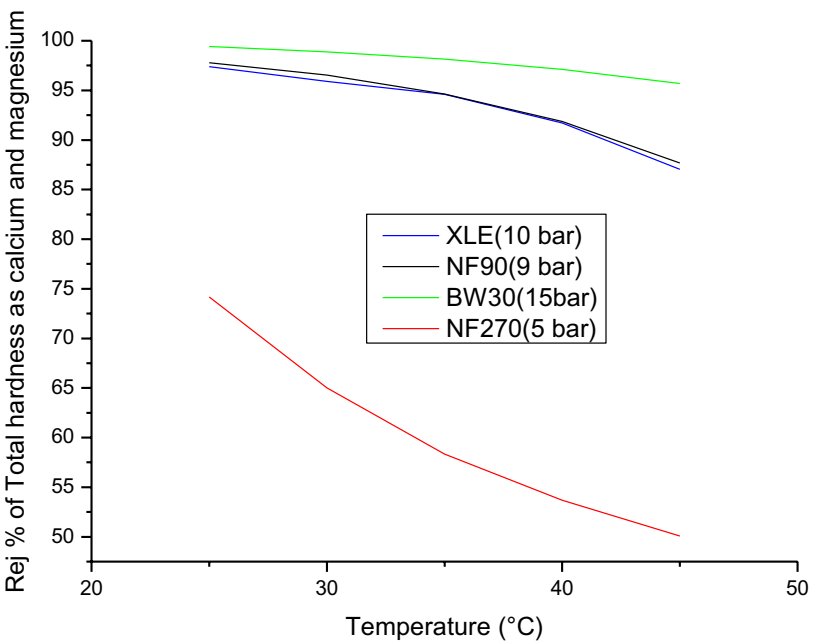

Fig. 10 Effect of temperature on $\mathrm{TH} \%$ removal at optimum feed pressure for conf a

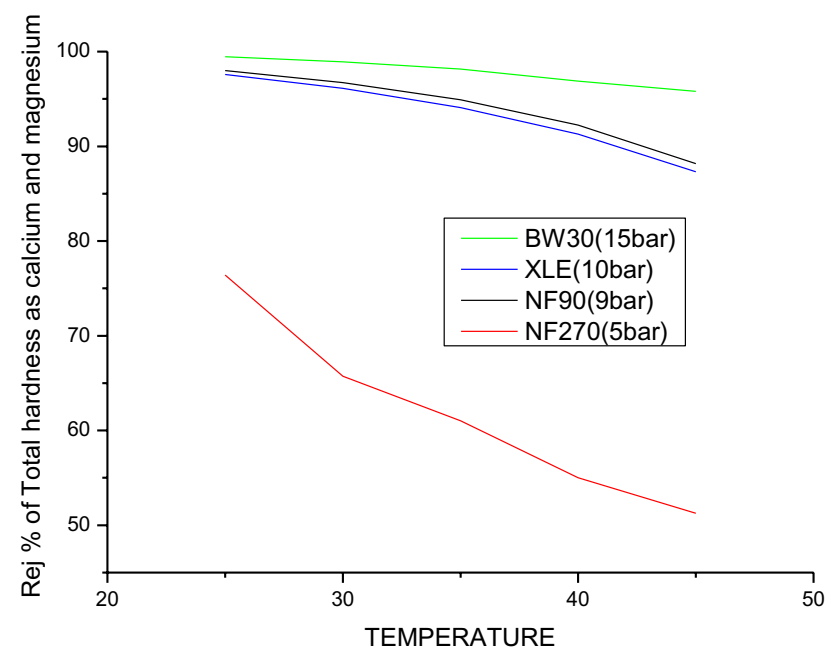

Fig. 11 Effect of temperature on $\mathrm{TH} \%$ removal at optimum feed pressure for conf $b$

process requirements. As described previously, in fact, $\mathrm{NaCl}$ concentration is a substantial parameter for ASP sludge performance. Unlike RO, NF process allows maintaining more than $30 \%$ of $\mathrm{NaCl}$ concentration in permeates. Moreover, $\mathrm{RO}$ membrane consumes approximately 50\% more energy than NF process at optimum feed pressure ( 9 bar). Therefore, RO is oversized regarding NF. NF270 doesn't obey to the EOR requirements regarding the total hardness at permeate outlet. As a result, the adequate membrane module is NF90 4040.

\section{Membrane configuration choice}

Two membrane configurations were investigated during this work for the chosen membrane module NF90

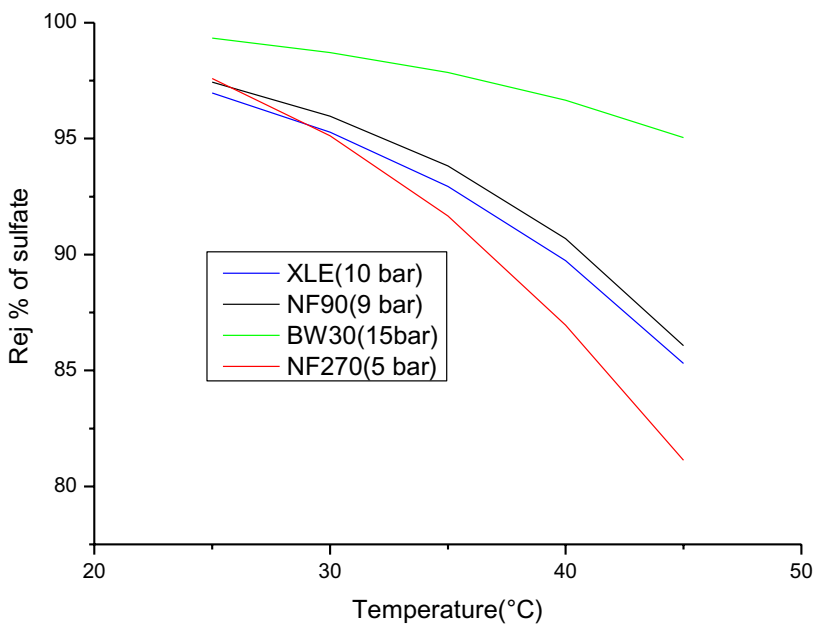

Fig. 12 Effect of temperature on sulfate \% removal at optimum feed pressure for conf a

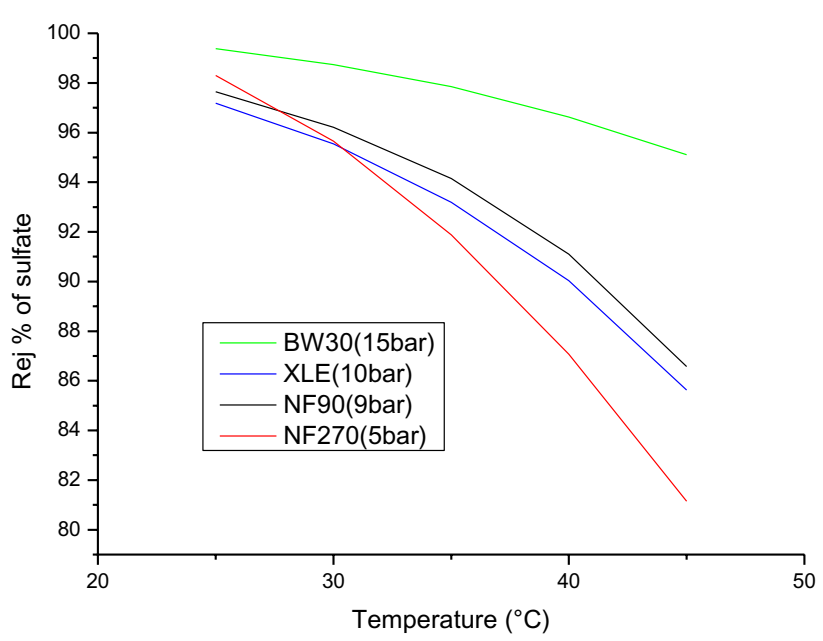

Fig. 13 effect of temperature on sulfate \% removal at optimum feed pressure for conf $b$

4040. In order to identify the most efficient configuration regarding RR, TDS, total hardness and sulfate removal percentage, Figs. 14, 15, 16 and 17 respectively, show that it follows the same pattern. Insignificant difference was observed between the configurations. It is explained by the low flow rate of the process. However, simulation results show imbalance in the input TDS between stages. Input TDS was up to $10998 \mathrm{ppm}$ for the first membrane module at 2nd stage, which might cause a fouling problem and require a systematic cleaning and antiscalant injection. Therefore, for a small range of flow rate, it is preferable to opt for one stage configuration with 3 modules PV to avoid fooling problems. 


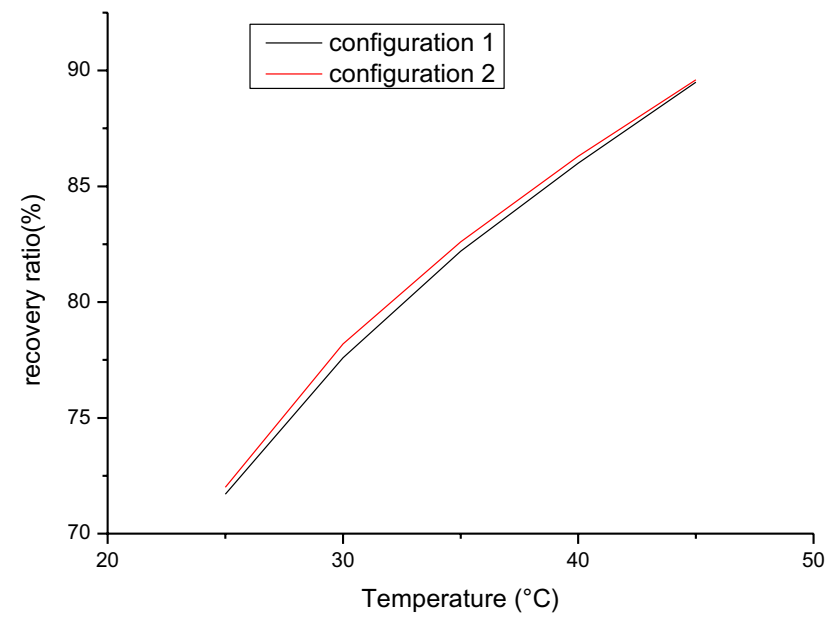

Fig.14 Comparison between conf a and conf $b$ on recovery ratio at optimum feed pressure

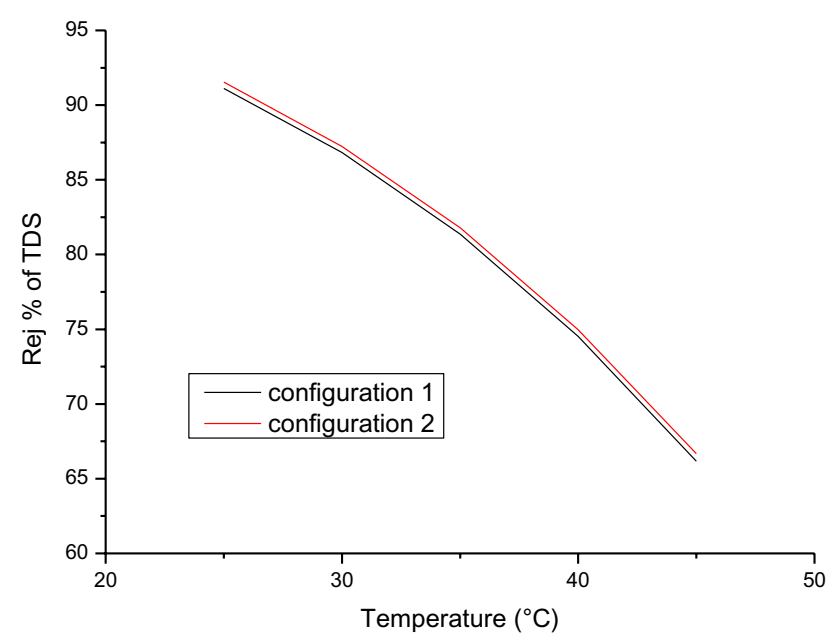

Fig. 15 comparison between conf a and conf 2 on $\%$ removal of TDS at optimum feed pressure

\section{Conclusion}

Two membrane processes were investigated.RO membrane BW30 provided the higher removal percentage of TDS, $\mathrm{TH}$ and sulfate, although, it was the most energy consuming. TH removal percentage was not enough to be used for ASP using NF270. XLE membrane provided acceptable removal percentage to be used for ASP. However, NF90 provided a better removal percentage than XLE with less energy consuming. As a result, RO membrane BW30 is oversized for EOR process. On the other hand, NF90 seems to be the most adequate membrane module. At this scale of study $\left(100 \mathrm{~m}^{3} / \mathrm{d}\right)$, insignificant difference between one and two stages configuration. To avoid

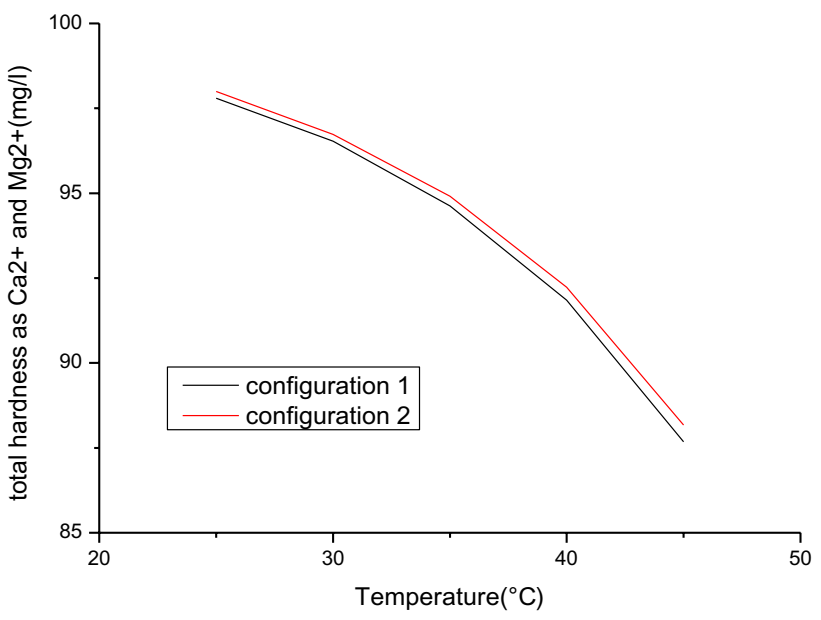

Fig. 16 comparison between conf a and conf $\mathrm{b}$ on $\mathrm{TH}$ removal $\%$ at optimum feed pressure

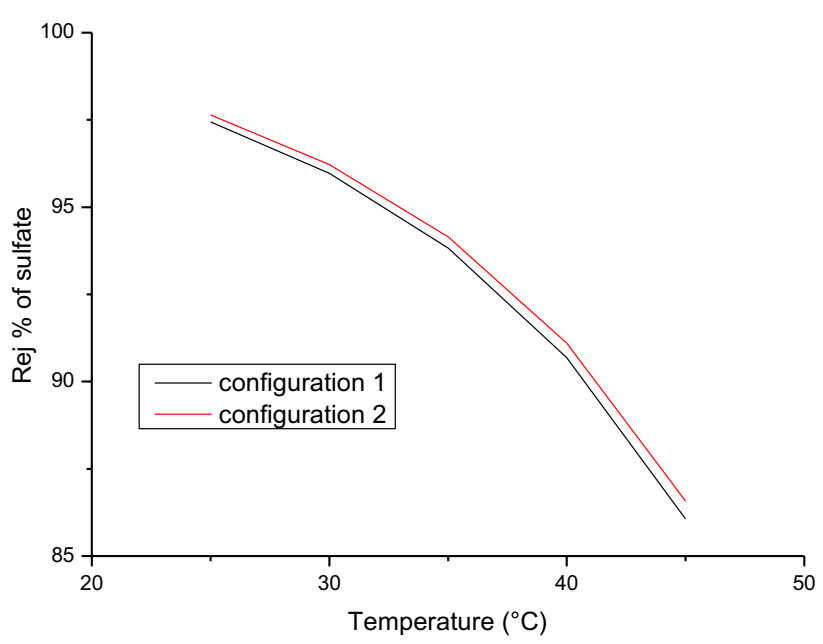

Fig. 17 Comparison between conf a and conf $\mathrm{b}$ on sulfate removal \% at optimum feed pressure

scaling problems, one stage configuration seems to be suitable choice. This work may be used as an operational tool as regard of temperature changing at field. Moreover, it could provide a solution for decision making concerning process option for on shore oilfield.

Acknowledgements The corresponding author would like to thank Algerian Petroleum Institute for all the facilities and research grants.

Funding The author(s) received no specific funding for this work.

\section{Declarations}

Competing interest The authors declare no conflict of interest to disclose. 
Open Access This article is licensed under a Creative Commons Attribution 4.0 International License, which permits use, sharing, adaptation, distribution and reproduction in any medium or format, as long as you give appropriate credit to the original author(s) and the source, provide a link to the Creative Commons licence, and indicate if changes were made. The images or other third party material in this article are included in the article's Creative Commons licence, unless indicated otherwise in a credit line to the material. If material is not included in the article's Creative Commons licence and your intended use is not permitted by statutory regulation or exceeds the permitted use, you will need to obtain permission directly from the copyright holder. To view a copy of this licence, visit http://creativecommons.org/licenses/by/4.0/.

\section{References}

Al-Obaidi M, Kara-Zaitri C, Mujtaba I (2018) Simultaneous removal of organic compounds from wastewater using RO process: modeling, simulation and optimization. International symposium on processsystems engineering, pp 1867-1872

Chang H, Yamming G (2013) Chemical injection facilities-from pilot test to field-wide expansion. SPE 165308
Dow (2021) Water \& Process Solutions, FILMTEC ${ }^{\text {TM }}$ Reverse Osmosis Membranes, Technical Manual

Henthorne L (2013). Developing and piloting water treatment technologies to address offshore EOR challenges. SPE 165241

Morrow N, Buckley J (2011) Improved oil recovery by low-salinity water flooding. J Petrol Technol 63:106-112

R\&D SONATRACH report (2017)

Sowgath T, Mujtaba I (2017) Design for reverse osmosis process for the purification of river water in the southern belt of Bangladesh. Chem Eng Trans 61(6):1159-1164

Zaid HM, Ahmad Latiff NR, Yahya N (2014) The effect of zinc oxide and aluminum oxide nanoparticles on interfacial tension and viscosity of nanofluids for enhanced oil recovery. Adv Mater Res 1024:56-59

Publisher's Note Springer Nature remains neutral with regard to jurisdictional claims in published maps and institutional affiliations. 